\title{
Effect of milk protein composition and amount of $\beta$-casein on growth performance, gut hormones, and inflammatory cytokines in an in vivo piglet model
}

\author{
N. Rafiee-Tari, ${ }^{1}$ M. Z. Fan, ${ }^{2}$ T. Archbold, ${ }^{2}$ E. Arranz, ${ }^{1}$ and M. Corredig ${ }^{1,3 *}$ \\ ${ }^{1}$ Department of Food Science, University of Guelph, Guelph N1G2W1, ON, Canada \\ ${ }^{2}$ Department of Animal Biosciences, University of Guelph, Guelph N1G2W1, ON, Canada \\ ${ }^{3}$ iFood Center, Department of Food Science, Aarhus University, Aarhus 8000, Denmark
}

\section{ABSTRACT}

The objective of this work was to better understand the effect of differences in milk protein composition, and specifically, a change in $\beta$-casein to total casein in a milk-based matrix, on growth performance and metabolic and inflammatory responses using a piglet model. Three formulas were optimized for piglets, with similar metabolizable energy, total protein content, and other essential nutrients. Only the protein type and ratio varied between the treatments: the protein fraction of the control diet contained only whey proteins, whereas 2 other matrices contained a whey protein to casein ratio of $60: 40$, and differed in the amount of $\beta$-casein (12.5 and $17.1 \%$ of total protein). Piglets fed formula containing whey proteins and caseins, regardless of the concentration of $\beta$-casein, showed a significantly higher average daily gain, average daily feed intake, and feed efficiency compared with piglets consuming the formula with only whey protein. Consumption of the formula containing only whey protein showed higher levels of plasma glucagon-like peptide-1 and ghrelin compared with the consumption of formula containing casein and whey protein. A positive correlation was observed between postprandial time and glucagon-like peptide-1 response. The intestinal pro-inflammatory cytokine tumor necrosis factor $\alpha$ increased significantly in piglets fed the whey protein/casein diet compared with those fed whey protein formula. All formula-fed piglets showed a lower level of IL-6 cytokine compared with the ad libitum sow-fed piglets, regardless of composition. No significant differences in the anti-inflammatory IL-10 concentration were observed between treatment groups. Milk protein composition contributed to the regulation of piglets' metabolic and physiological responses, with whey protein/casein formula promoting

Received October 2, 2018.

Accepted May 29, 2019.

*Corresponding author: mc@food.au.dk growth performance and a different immune regulatory balance compared with a formula containing only whey protein. Results indicated no differences between treatments containing different levels of $\beta$-casein.

Key words: milk protein, $\beta$-casein, model infant formula, piglet model, growth performance

\section{INTRODUCTION}

The food matrix can play an important role in altering the release and absorption of nutrients during digestion, causing changes in the physiological responses. Bovine milk is known as a highly digestible source of nitrogen and AA. The main milk protein types, whey proteins (WP) and casein (CN), have different compositions and digestibilities; the $\mathrm{CN}$-derived peptides are more slowly absorbed than WP-derived peptides. These peptides have been shown to have different metabolic effects, for example, a different effect on satiety (Boirie et al., 1997). Whey protein consumption has also been linked to a higher level of satiety-related gastrointestinal hormone glucagon-like peptide-1 (GLP-1) and cholecystokinin, compared with CN consumption (Hall et al., 2003; Luhovyy et al., 2007).

The effect of milk protein composition in dairy matrices may be of great importance in stages of life where physiological changes occur, as for example, during the early development and growth of the neonate. A wide range of bioactive peptides are released during digestion of CN and WP. These peptides, depending on their AA composition, sequence, and degree of hydrolysis, may exert a multitude of biological functions, either locally in the gastric milieu or after being absorbed and released into the blood (Korhonen and Pihlanto, 2003; Horner et al., 2016).

Many of milk bioactive peptides have multifunctional properties; for example, peptides derived from the 60 to 70 portion of $\beta$-CN sequence are known to exert immunomodulatory, opioid, and angiotensin converting enzyme-inhibitory functionalities (Meisel, 2005). Beta- 
casomorphine peptides with opioid activity also induce anti-inflammatory responses in mice (de Noni, 2008; Ul Haq et al., 2014). The immunomodulatory activities from several $\mathrm{CN}$ and WP-derived bioactive peptides have been widely addressed in the literature (Gill et al., 2000; Fitzgerald and Meisel, 2003; Korhonen and Pihlanto, 2003). The gastrointestinal immune system is the largest secondary immune organ of the body and its development during the neonatal period is affected by milk-derived peptides (Gill et al., 2000). These peptides contribute to immune regulation by enhancement of immune cell functions via stimulating secretion of antibodies, inflammatory cytokines, or specific enzymes (Lönnerdal, 2013).

Numerous bioactive peptides originating from digestion of dietary proteins have been observed in the gut or the bloodstream (Barbé et al., 2014), or their formation has been observed through static or dynamic in vitro digestion methods, the details of the effect of the individual peptides on the host are still not fully understood. It is possible to hypothesize that protein compositional dissimilarities may bring different responses in naturally developing immune systems. Protein compositional dissimilarities are known between bovine milk, as the main source of protein for making infant formula, and human milk. Although CN make up approximately $80 \%$ of the total protein in bovine milk, they only comprise $40 \%$ of the protein in mature human milk (Thompkinson and Kharb, 2007). $\beta$-Casein is the major $\mathrm{CN}$ in human milk, making up about $65 \%$ of total CN, while up to $35 \%$ in bovine milk (Park and Haenlein, 2006). Whey proteins (WP) comprise about 20 and $60 \%$ of bovine and human milk protein, respectively.

For the released bioactive peptides to exert their functional effects, it is crucial that they survive proteolysis during digestion. Recent in vivo work suggested that $\beta$-CN may be of physiological significance as some bioactive peptides derived from $\beta-\mathrm{CN}$ were recovered in the small intestine at later stages of digestion and in larger concentrations than those originated from the other CN (Bouzerzour et al., 2012; Barbé et al., 2014). Some of the detected sequences from $\beta-\mathrm{CN}$ were related to immunomodulatory, opioid, and antihypertensive activities, through former in vitro and in vivo experiments (Barbé et al., 2014). There is evidence of resistance of human milk $\beta$-CN toward digestion at infants' gastric $\mathrm{pH}$ of about 4 (Chatterton et al., 2004). Many of the studies on the influence of food composition on immunoregulatory functions, particularly on the expression of inflammatory cytokines, are carried out using stimuli to induce inflammatory responses (Herfel et al., 2011; Kume et al., 2012; Fan et al., 2012; Chatterton et al., 2013).
The aim of the current study was to investigate the metabolic and physiological responses of piglets to a model food matrix containing either WP as the only protein source (WP-based formula), or WP to $\mathrm{CN}$ at a ratio of 60:40 (WP-CN formula), with different amounts of $\beta$-CN while maintaining the same concentration of total CN. Growth performance, feed intake, as well as plasma concentrations of satiety-related hormone, GLP-1, and appetite-related hormone, ghrelin, were evaluated. Concentrations of cytokines IL-6, IL-10, and tumor necrosis factor (TNF)- $\alpha$ in the intestinal tissue were also measured. Increases in gut local and blood systemic concentrations of IL- 6 and TNF- $\alpha$ are indicators of acute and adaptive pro-inflammatory responses, whereas increases in IL-10 in the intestinal tissue would be indicative of adaptive anti-inflammatory responses (Fan et al., 2012; Lackeyram et al., 2017). It was indeed hypothesized that a difference in the protein composition of the matrix would affect the immunomodulatory response. A piglet model was used, as it is an established model for human infants' nutrition and digestion, due to the gastrointestinal morphological and physiological similarities (Miller and Ullrey, 1987; Moughan et al., 1992).

\section{MATERIALS AND METHODS}

\section{Diet Composition}

Skim milk was fractionated using microfiltration at $4^{\circ} \mathrm{C}$ and warm temperatures to obtain milk concentrates containing different levels of $\beta$-CN (Rafiee Tari et al., 2018). Whey protein isolate, containing a minimum of 90\% protein (WPI 90), and lactose (Leprino Foods, Denver, CO), soybean oil, vitamins, and minerals (Sigma-Aldrich, St. Louis, MO, and Grober Nutrition, Cambridge, ON, Canada) were added to the milk base to obtain liquid diets that met the nutritional requirements of newborn pigs (National Research Council, 2012), as summarized in Table 1. The samples were used after ensuring microbiological safety, by analyzing total viable cell count, total coliforms, and Escherichia coli, plated onto aerobic plate count and E. coli/coliform Petri Films (3M Canada, London, ON, Canada; according to Health Canada MFHPB-43 protocol; results not shown). The samples were homogenized at 13.8 and $3.4 \mathrm{MPa}$, and pasteurized at $72^{\circ} \mathrm{C}$ for $30 \mathrm{~s}(\mathrm{Mi}-$ crothermics Inc., Raleigh, NC), packed in 1-L bottles, and stored frozen until required.

\section{Animals and Experimental Design}

The study was conducted at the University of Guelph, Animal Science facility. All animal trials were approved 
by the University of Guelph's Animal Care Committee and were conducted in compliance with the Canadian Council of Animal Care guidelines. A total of 32 crossbred (York $\times$ Landrace $\times$ Duroc) piglets from the Arkell Swine Research Station (University of Guelph, ON, Canada) were selected from the larger litters of 8 sows. The piglets had an average initial BW of 1,844 \pm $20 \mathrm{~g}$ at $3 \mathrm{~d}$ of age, similar to other studies (Bouzerzour et al., 2012); the piglets were selected in this weight range to minimize the effect of a large initial weight variation. The study was performed over 2 blocks of 16 piglets, separated by a 10-d gap. All piglets were randomly allocated to 4 groups of 4 , with one group remaining at the farm with their sow to eat ad libitum from their sow's milk, as a reference group for growth performance and physiological factors.

The experimental design was a randomized block design with a $4 \times 2$ factorial arrangement of 4 treatment groups and 2 blocks. However, for statistical analysis, only the 3 treatment groups were considered (see below). In each block, 12 piglets were randomly allotted to 3 formula groups of 4 , including 2 gilts (female) and 2 barrows (male). Four more piglets remained at the farm and were left with their own sow. Of note, the first and second block of piglets were euthanized 60 and 120 min after the last meal, and the effect of postprandial time on the plasma concentration of satiety-related hormone GLP-1 was studied.

The 12 piglets in each block which were allotted to 3 formula groups, were separated from their mothers at 3 $\mathrm{d}$ of age, were transported to the animal science facility, and were individually housed in metabolic cages in an environmentally controlled room with ambient temperature at $26^{\circ} \mathrm{C}$ and $16: 8 \mathrm{~h}$ light:dark cycle. Each cage was provided with a bowl fixed to the bottom of the cage in a way that piglets could ingest food conveniently, and the bowl was not removed until it was empty. Piglets were fed for $18 \mathrm{~d}$ until the age of $21 \mathrm{~d}$. This feeding period was chosen as the age between 2 to $4 \mathrm{wk}$ is used to wean piglets and often used to evaluate their immune response, growth performance (Boudry et al., 2008; de Lange et al., 2010; Young et al., 2010), or digestive functions (Bouzerzour et al., 2012).

To avoid the effects of variation in feed intake among treatment groups, a consistent feeding allowance and schedule was applied to all piglets during the study. Piglets' BW were recorded every other day, and daily liquid food allowance was calculated based on $60 \%$ of the BW to meet the requirements for piglets (NRC, 2012). Frozen formulas were defrosted at refrigeration temperature for 48 to $72 \mathrm{~h}$ before being administered to the piglets.

The liquid formula was then warmed up to about $35^{\circ} \mathrm{C}$ before feeding (Moughan et al., 1991), by putting the bottles in the water bath. Piglets were fed 5 times a day during the first week $(0800,1200,1600,2000$, and $0000 \mathrm{~h})$ and 4 times a day after that $(0800,1300$, 1800, and $0000 \mathrm{~h}$ ). Feed intake was recorded for each piglet after each meal by measuring and subtracting the volume of food left.

The feed intake amounts throughout the experimental period were used to calculate average daily feed intake (ADFI). Body weights measured at the beginning and end of the trial were used for the calculation of ADG. Using the values for ADG and ADFI, feed conversion ratio was recorded for each piglet by calculating feed: gain ratio $(\mathbf{F}: \mathbf{G})$.

After administering the last meal on d 21 to piglets, they were kept for 60 min (block 1) or 120 min (block 2) before being killed. For the piglets fed ad libitum at the farm, this time was not controlled. The number of animals used in this study was reviewed by the animal care committee and was similar to other published work (Kim et al., 2009; Bouzerzour et al., 2012).

Table 1. Composition of the 3 model liquid formulas: whey protein (WP) and WP-CN formulas containing 2 different concentrations of $\beta-\mathrm{CN}^{1}$

\begin{tabular}{|c|c|c|c|}
\hline Calculated nutrient content & WP-based & Low $\beta-\mathrm{CN}$ & High $\beta-\mathrm{CN}$ \\
\hline WP:CN ratio & 100:0 & $60: 40$ & $60: 40$ \\
\hline $\mathrm{DM}(\%)$ & 9.78 & 9.78 & 9.78 \\
\hline ME (Mcal/kg) & 3.4 & 3.3 & 3.3 \\
\hline Total protein $(\mathrm{g} / \mathrm{kg})$ & 28.1 & 28.0 & 28.0 \\
\hline$\beta-\mathrm{CN}(\mathrm{g} / \mathrm{kg})$ & 0.0 & 3.5 & 4.8 \\
\hline$\beta-\mathrm{CN}(\mathrm{g} / 100 \mathrm{~g}$ of protein $)$ & 0.0 & 12.5 & 17.1 \\
\hline Total fat $(\mathrm{g} / \mathrm{kg})$ & 85 & 84 & 84 \\
\hline Lactose $(\mathrm{g} / \mathrm{kg})$ & 502 & 496 & 496 \\
\hline Total Ca $(\mathrm{mg} / \mathrm{kg})$ & 168 & 167 & 167 \\
\hline Total P $(\mathrm{mg} / \mathrm{kg})$ & 164 & 163 & 163 \\
\hline Total Mg (mg/kg) & 226 & 224 & 224 \\
\hline Total K ( $\mathrm{mg} / \mathrm{kg})$ & 49 & 48 & 48 \\
\hline Total Na $(\mathrm{mg} / \mathrm{kg})$ & 0.3 & 0.3 & 0.3 \\
\hline
\end{tabular}

${ }^{1}$ Values are all reported as \% of DM. 


\section{Euthanizing and Sampling}

Other than eating behavior and BW, clinical evaluations were made daily to monitor the animals' overall well-being and stool consistency.

At $21 \mathrm{~d}$ of age, the piglets were anesthetized with inhaled isofluorane and killed via an intracardiac injection of pentobarbital (Sigma-Aldrich, Oakville, ON, Canada) at $0.3 \mathrm{~mL} / \mathrm{kg}$ of BW (Young et al., 2010). Each block was euthanized within $2 \mathrm{~d}$, on each day, 8 piglets, which included 1 male and 1 female from each treatment group.

Just before the animals were killed, blood samples were collected, via the periorbital sinus, in lithiumheparin-coated tubes (BD Vacutainer, Franklin Lakes, $\mathrm{NJ}$ ), kept on ice, and centrifuged at 2,500 $\times g$ for 15 min at $4^{\circ} \mathrm{C}$. The separated plasma was aliquoted and stored at $-80^{\circ} \mathrm{C}$ until further analyses.

Intestinal tissues were separated and immediately flushed with ice-cold saline containing $0.1 \mathrm{mmol} / \mathrm{L}$ of phenylmethysulfonyl fluoride. The intestine was excised, and samples of proximal jejunum were taken and flash frozen in liquid nitrogen and stored at $-80^{\circ} \mathrm{C}$. Stomach contents were removed.

\section{Plasma Hormones and Intestinal Inflammatory Cytokine Concentration Assay}

Plasma concentrations of gut hormones GLP-1 and ghrelin were measured in duplicate using porcinespecific ELISA kit (Neo Scientific, Cambridge, MA), according to the manufacturer's instructions. The sensitivity limits of the ELISA kits were $1.0 \mathrm{pg} / \mathrm{mL}$ for GLP-1 and $1.0 \mathrm{ng} / \mathrm{mL}$ for ghrelin.

Tissue samples were finely ground in liquid nitrogen using a mortar and pestle. Tissue homogenate was prepared by homogenizing $1 \mathrm{~g}$ of ground, flash-frozen jejunal tissue in $2 \mathrm{~mL}$ of Hanks' balanced salt solution (HyClone, GE Healthcare Life Sciences, Logan, UT) and $20 \mu \mathrm{L}$ of Halt protease inhibitor cocktail (Thermo Scientific, Rockford, IL), using a Powergen handheld homogenizer (Fisher, Pittsburgh, PA). The homogenate was immediately centrifuged at $12,000 \times g$ at $4^{\circ} \mathrm{C}$ for $10 \mathrm{~min}$, and the supernatant was used to determine the cytokine concentration. Absorbance was read using a microplate reader (BioTek Instruments Inc., Winooski, VT). Concentration of inflammatory cytokines TNF- $\alpha$, IL-10, and IL-6 were measured in duplicate using ELISA kits (R\&D systems, Minneapolis, MN), according to the manufacturer's instructions. The sensitivity limits of the ELISA kits were $5 \mathrm{pg} / \mathrm{mL}$ for TNF- $\alpha, 5.5 \mathrm{pg} / \mathrm{mL}$ for IL-10, and $4.3 \mathrm{pg} / \mathrm{mL}$ for IL-6, as confirmed by the manufacturer, for jejunal tissues. The concentrations of the studied inflammatory cytokines and gut hormones were measured from reference curves generated in each individual assay with reference standards of known concentrations provided in the ELISA kits.

\section{Statistical Analysis}

All data were statistically analyzed using PROC GLM of SAS/STAT 9.4 (SAS Institute Inc., Cary, NC). Interactions of diet, sex, and block were tested for possible effects. No effects of block (factors affecting the blocks such as genetic variation and the month of the year, time of sampling in relation of feeding) were observed, and thus were excluded from the overall model. The effect of diet on ADG, ADFI, F:G, inflammatory cytokines, and gut hormones were analyzed by oneway ANOVA. In the case of gut hormone GLP-1, the 2 blocks were analyzed separately to study the effect of postprandial time (60 and $120 \mathrm{~min}$ ) on this satietyrelated hormone. The concentration of postprandial ghrelin was analyzed after 120 min of digestion due to a limited sample amount.

A post hoc Tukey's test was used to analyze differences between groups. Differences were deemed significant when $P \leq 0.05$, and trends were noted when 0.05 $\leq P \leq 0.1$. Sow-fed piglets, albeit used as a reference, were excluded from the statistical analysis, as they were fed ad libitum, whereas other piglets were fed on a consistent schedule and allowance.

\section{RESULTS}

During the study, piglets showed overall good health. No mortality occurred during the study. Sow-fed piglets were not considered in the comparison because they were fed ad libitum.

\section{Growth Performance and Feed Intake}

Figure 1 summarizes the results of growth performance. The ADG is shown in Figure 1A. In addition to the 3 treatments, the ADG for the suckling piglets fed ad libitum is also reported as a reference. Piglets fed formulas containing WP-CN had a higher ADG than piglets fed the WP-based formula. Suckling piglets had a higher ADG than all formula-fed piglets, reaching values around $300 \mathrm{~g} / \mathrm{d}$, but their intake was not controlled as for the experimental treatments. No significant differences were observed in ADG between the 2 groups fed WP-CN formula, regardless of the amount of $\beta-\mathrm{CN}$.

The ADFI was also monitored for the piglets allocated to the 3 liquid formula treatments (Figure 1B). The WP-CN formulas improved ADFI in piglets as 

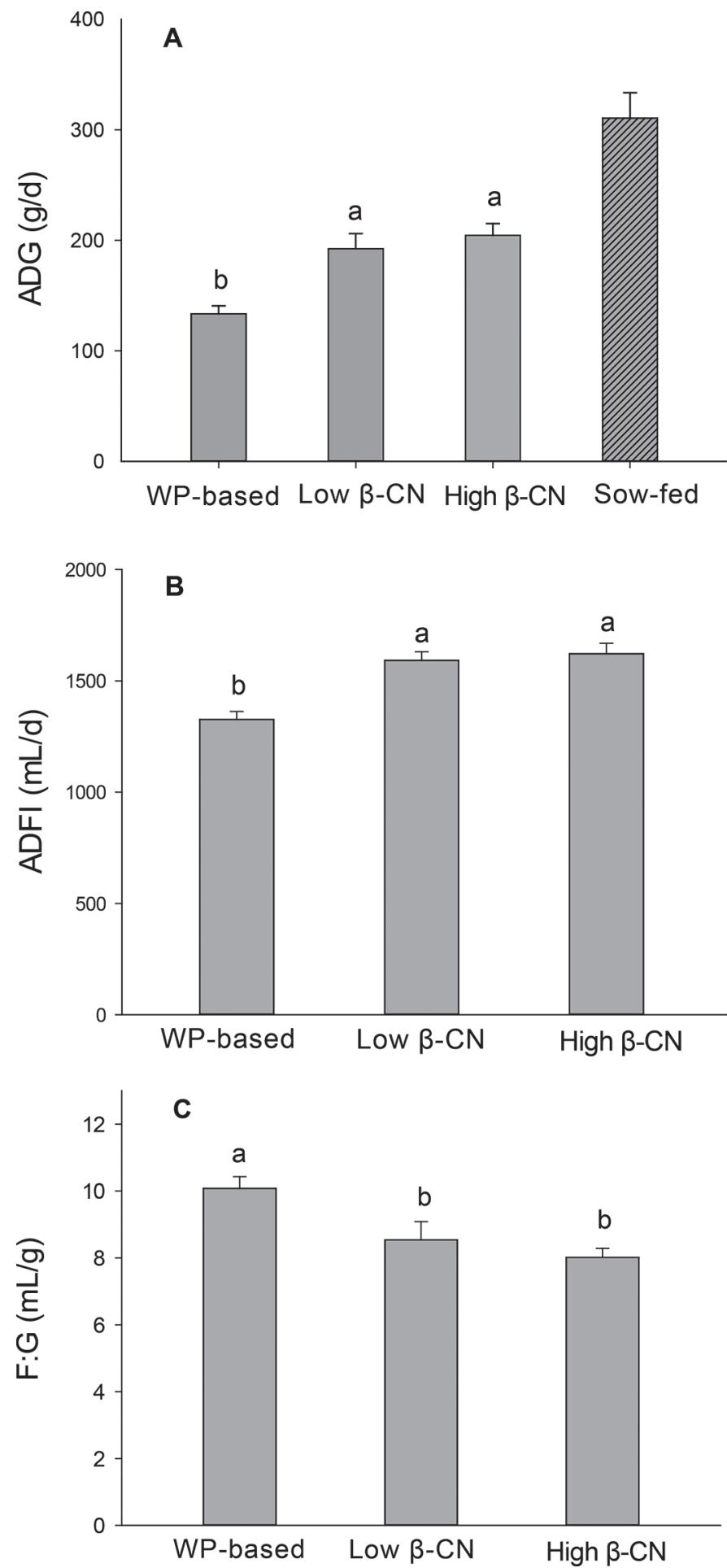

Figure 1. Average daily gain (A), average daily feed intake (ADFI; $\mathrm{B}$ ), and feed-to-gain ratio (F:G; C) of piglets fed whey protein (WP)based formula or WP-CN formulas containing high or low $\beta-\mathrm{CN} /$ total $\mathrm{CN}$ ratio. Values represent means $\pm \mathrm{SEM}, \mathrm{n}=8$. Different letters indicate a significant difference $(P<0.05)$. The data for the sow-fed piglets were not included in the statistical data analyses due to ad libitum feeding and are only shown for comparison purposes. compared with the WP formula group. The piglets fed WP-CN formula showed an ADFI of $1,606 \mathrm{~mL} / \mathrm{d}$, compared with an average of $1,326 \mathrm{~mL} / \mathrm{d}$ in WP-based-fed piglets. Depending on the formula, it is clearly shown that although ADG and ADFI were both lower in the WP diet group, a higher F:G was still observed for piglets fed the WP diet (Figure 1C). This demonstrates that a similar amount of feed resulted in a higher weight gain in WP-CN-fed piglets than in WP-based group. In other words, the increase in the ADG was greater than the increase in ADFI in piglets fed WP-CN diets. No significant differences were observed between the 2 $\beta-\mathrm{CN}$ treatments.

\section{Plasma Concentration of GLP-1 and Ghrelin}

Postprandial plasma GLP-1 concentrations after 60 and $120 \mathrm{~min}$ from the last meal in response to the different diets are shown in Figure 2. The plasma GLP-1 concentration of piglets fed WP-based formula was significantly higher than the 2 groups fed WP-CN formula, both after 60 or 120 min from the last meal $(P<$ $0.05)$. Postprandial time was positively associated with plasma GLP-1 concentration for all treatments, with a significant increase of plasma GLP-1 concentration after 120 min compared with 60 min postprandial time.

No significant difference was observed in GLP-1 concentration between high and low $\beta-\mathrm{CN}$ diet groups at $60 \mathrm{~min}$. Conversely, at $120 \mathrm{~min}$ from the last meal,

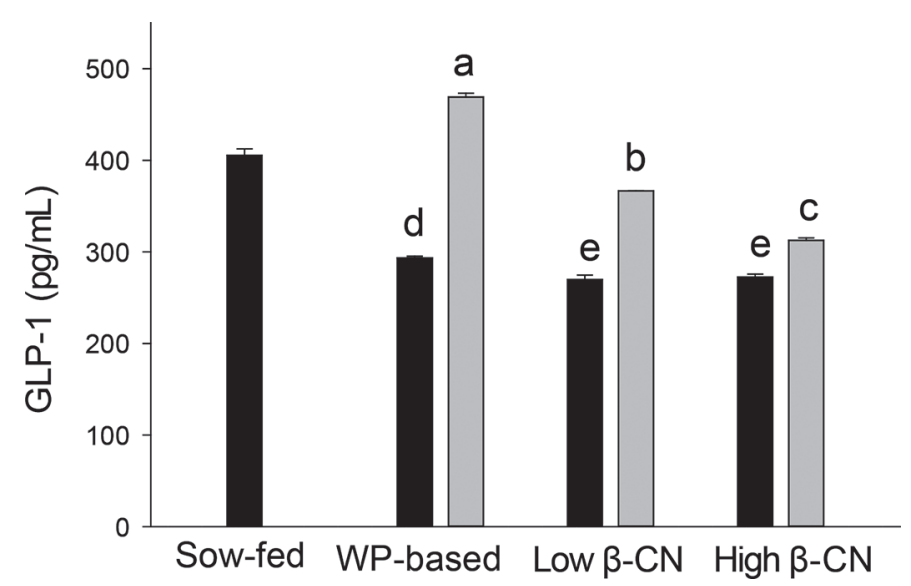

Figure 2. Plasma glucagon-like peptide-1 (GLP-1) concentration measured in the 2 blocks for piglets killed after 60 (black bars) or 120 (gray bars) min after the last meal. Piglets were fed sow milk (ad libitum), whey protein (WP)-based formula, or WP-CN-based formulas containing high or low $\beta-\mathrm{CN} /$ total $\mathrm{CN}$ ratio. Values represent means \pm SEM $(\mathrm{n}=4)$. Different letters indicate a significant difference $(P$ $<0.05)$. 
plasma GLP-1 concentration was lower in high $\beta-\mathrm{CN}$ diet group compared with low $\beta-\mathrm{CN}$.

In addition to GLP-1, the concentration of ghrelin was also measured in the plasma of piglets killed after 120 min from the last meal (Figure 3). The postprandial ghrelin concentration in the WP-based formula treatment groups was higher than that in the group fed WP-CN formulas. There was no control over postprandial time for sow-fed piglets. Therefore, for this group, an average GLP-1 and ghrelin concentration of the 2 experimental blocks is shown in Figures 2 and 3, for comparison purposes only.

\section{Jejunal Concentration of IL-6, TNF- $\alpha$, and IL-10}

Concentrations of pro-inflammatory cytokines IL-6 and TNF- $\alpha$, and the anti-inflammatory cytokine IL-10 were measured in the proximal jejunum tissue of the piglets, and the results are summarized in Figure 4 . The levels of TNF- $\alpha$ in the tissue were significantly elevated in the WP-CN diet piglets, as compared with the WP formula group. However, no significant difference was observed in the TNF- $\alpha$ concentration between low and high $\beta-\mathrm{CN}$ formula groups. A higher jejunal concentration of TNF- $\alpha$ was observed in sow-fed piglets compared with the WP formula group.

Sow-fed piglets showed a higher jejunal concentration of IL-6 compared with piglets fed either WP-based or WP-CN formulas. No significant difference in jejunal IL-6 concentration was observed between WP, high $\beta$-CN, and low $\beta$-CN formula groups.

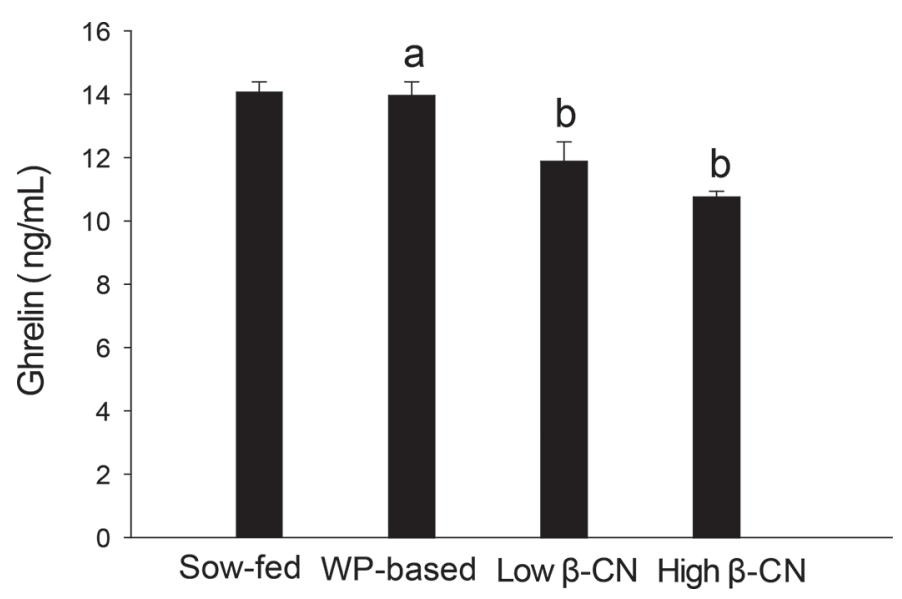

Figure 3. Plasma ghrelin concentration 120 min after the last meal. Piglets were fed sow milk (ad libitum), whey protein (WP)-based formula, or WP-CN-based formulas containing high or low $\beta$ - $\mathrm{CN} /$ total $\mathrm{CN}$ ratio. Values represent means \pm SEM $(\mathrm{n}=4)$. Different letters indicate a significant difference $(P<0.05)$.
Moreover, no statistically significant difference was evident in the jejunal concentration of IL-10 between all treatment groups.

\section{DISCUSSION}

A clear difference was observed in growth performance and feed intake between piglets fed WP and WP-CN
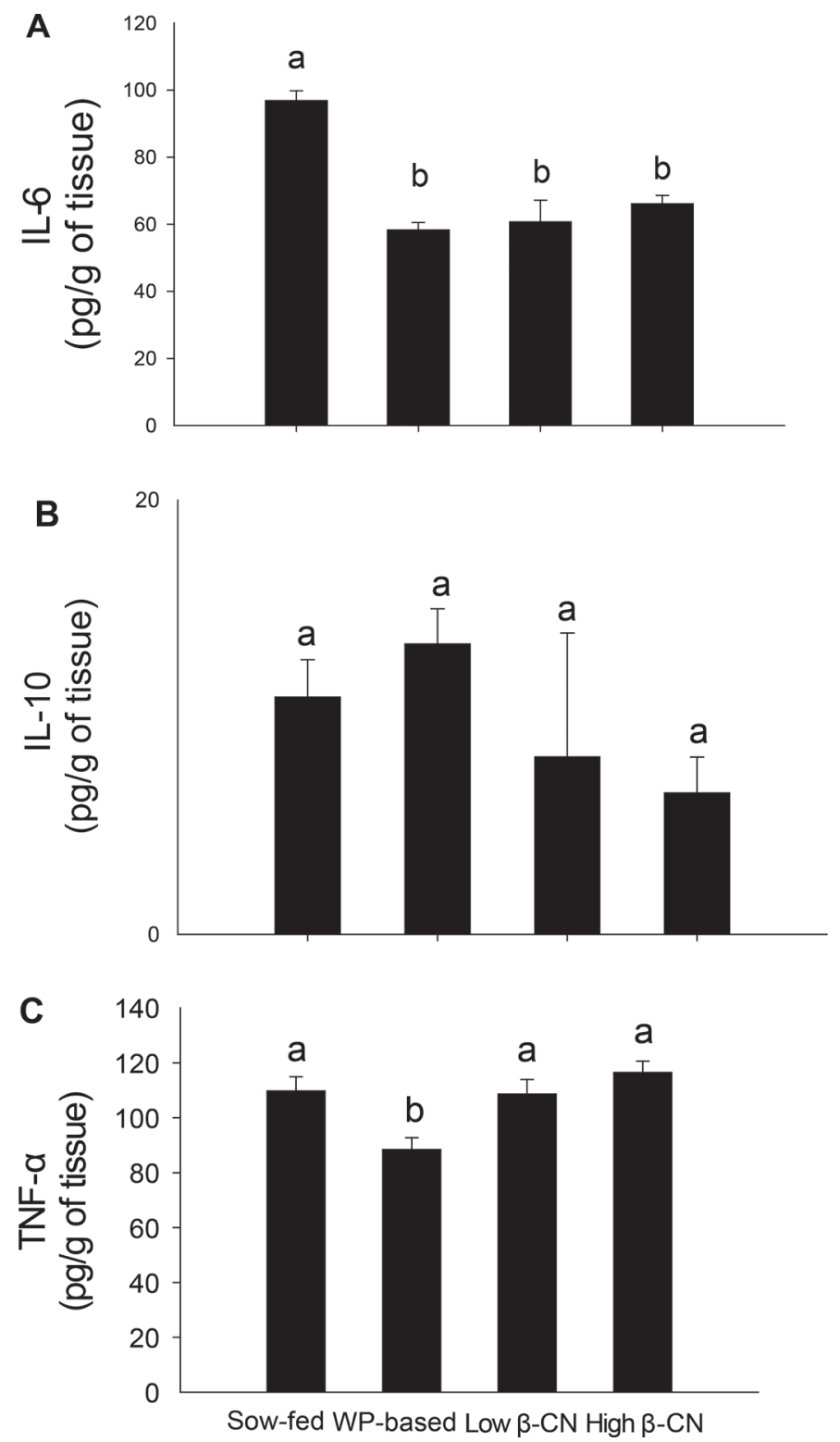

Figure 4. Concentration of IL-6 (A), IL-10 (B), and tumor necrosis factor (TNF)- $\alpha(\mathrm{C})$ in the proximal jejunum of 21-d-old piglets fed sow milk, whey protein (WP)-based formula, or WP-CN-based formulas containing high or low $\beta-\mathrm{CN} /$ total $\mathrm{CN}$ ratio. Values represent means \pm SEM $(\mathrm{n}=8)$. Different letters indicate a significant difference $(P$ $<0.05)$. 
diets, regardless of $\beta-\mathrm{CN}$ level: $\mathrm{ADG}$ and $\mathrm{ADFI}$ were significantly higher in piglets fed the WP-CN diets. Furthermore, the F:G was lower for the piglets fed the WP-CN formula compared with those fed WP-based formula. In other words, the same amount of WP-CN formula as WP-based resulted in a higher body mass in the piglets. It was therefore concluded that diets including both WP and CN resulted in a higher feed efficiency compared with the WP diet. These results are in agreement with previously published work demonstrating that in obese rats, when milk proteins were used to supplement an egg white diet to improve the energy balance, the feed intake and BW decreased more rapidly and for a longer period when feeding a diet containing WP, compared with a diet including both WP and CN (Pezeshki et al., 2015). In contrast, increasing WP to $\mathrm{CN}$ ratio of conventional infant formula with WP:CN ratio of 60:40 to 70:30 in an isocaloric formula was shown to improve energy efficiency or lower protein:energy ratio in human infants (Räihä et al., 2002; Fleddermann et al., 2014). This was attributed to the higher protein quality, that is, digestibility and AA composition of WP compared with CN, and in particular, providing the limited AA tryptophan from $\alpha$-LA (Fleddermann et al., 2014). This work clearly supported the hypothesis that different protein ratios affect feed intake; however, it did not demonstrate that at the level tested, there was an effect of $\beta-\mathrm{CN}$ ratio to total CN.

The lower feed intake observed in piglets fed WPbased formula can be attributed to a higher satiating effect of WP, compared with CN. It has been reported that WP and CN show different gastric emptying rates and digestive and absorptive functions (Hall et al., 2003), as CN coagulate under the gastric conditions and exhibit a lower gastric emptying rate, whereas WP remain soluble with a faster transfer to the upper intestine (Billeaud et al., 1990; Boirie et al., 1997). Preparations containing a WP to $\mathrm{CN}$ ratio of 60:40 result in a gastric digesta with higher viscosity and modulus than WP preparations (Rafiee Tari et al., 2018).

The lower feed intake observed in piglets fed WPbased formula could be attributed to poor palatability. In the present study, almost no food refusal was observed for the piglets fed WP-CN diets, whereas leftover food was observed for the WP-based diet. It is difficult to ascertain how poor palatability or satiety are responsible for a lower feed intake for WP-based formula. Indeed, the GLP-1 concentration in the plasma of the piglets fed the WP diet was higher compared with that of the piglets fed the WP-CN diet, regardless of the postprandial time (60 or $120 \mathrm{~min}$ ). This effect has been shown in humans (Hall et al., 2003). In rats it has been shown to be related to a greater glucose clearance (Pezeshki et al., 2015). The GLP-1 is a satiety-related hormone regulating processes such as glucose metabolism, appetite, and feed intake. The present work also showed a significant increase of plasma GLP-1 concentration with postprandial time (120 min compared with 60 min), regardless of the diet, in agreement with previous literature (Overduin et al., 2013; Ripken et al., 2015).

Ghrelin concentration in the plasma was also measured in the piglets killed after $120 \mathrm{~min}$ from the last meal. Ghrelin is an appetite-related, orexigenic gut hormone that contributes to the regulation of food intake. Its concentration in plasma is suppressed after a meal (Pusztai et al., 2008; Gibbons et al., 2013). It has been shown that WP and CN induce similar changes in plasma ghrelin of healthy adults (Veldhorst et al., 2009). In the piglet, there was a lower level of ghrelin with WP-CN diets compared with WP. It was also previously reported that an increased secretion of GLP-1 could reduce the acute production of appetite-related ghrelin (Overduin et al., 2013). Again, as mentioned above, a different level of $\beta$-CN did not affect the concentration of these biomarkers.

Hence, when looking at the secretion of GLP-1, it could be hypothesized that the lower feed intake observed in piglets fed WP-based formula was related to the higher satiating effect of WP, compared with $\mathrm{CN}$. The WP and CN show different gastric emptying rates, as CN coagulate in the stomach environment, whereas WP remain soluble and transfer faster to the upper intestinal tract (Billeaud et al., 1990; Boirie et al., 1997). The difference in composition of the proteins contributes to differences in the physical properties of the curd (Rafiee Tari et al., 2018).

The effect of physiological responses to diets containing different milk protein matrices is still not fully understood. In this work, it was hypothesized that the difference in protein composition, and concentration of $\beta-\mathrm{CN}$ relative to total $\mathrm{CN}$, may result in a different immunoregulatory response. Food proteins play an important role in the development of the gut immune system. Several bioactive peptides encrypted in CN and WP have been shown to have immunomodulatory functions, and many of these functions are exerted through regulation of immune cells and secretion of inflammatory cytokines (Korhonen and Pihlanto, 2003). Inflammatory cytokines in the early stages of life act as regulators in the development of gut immune system at later stages of life (Boudry et al., 2013). The effect of dietary proteins and the released bioactive peptides during digestion on inflammatory responses have been mostly exhibited upon pre-stimulation and inflammatory induction, such as oxidative stress, microbiological 
induction, or using high fat or protein diets (Young et al., 2010; Fan et al., 2012; Chatterton et al., 2013). Information in the literature is very limited on the effect of protein composition of a dairy matrix with the same protein concentration, on the gastrointestinal milieu, in physiological conditions, whereby the inflammatory responses are not induced.

No changes were observed in the concentration of anti-inflammatory IL-10 in the proximal jejunum. The results are in agreement with previous work that showed no influence of CN and WP diets on IL-10 mRNA levels, in response to lipopolysaccharide in colonic tissue cultures in pigs (Boudry et al., 2013). All formulas, regardless of composition, showed a lower induction of IL-6 response compared with the sow-fed piglets. However, there was a higher concentration of TNF- $\alpha$ in the proximal jejunum of the piglets fed WP-CN diets, compared with the WP-based diet group. The formula containing both $\mathrm{WP}$ and $\mathrm{CN}$ may promote a pro-inflammatory milieu in the newborn piglets, when compared with the WP-based diet. This is consistent with the fact that several peptide sequences originated from $\mathrm{CN}$ during digestion, exerting immune-modulatory activities survive the digestion process (Chatterton et al., 2013). There were no differences between the 2 WP-CN matrices, regardless of the $\beta-\mathrm{CN}$ ratio to total $\mathrm{CN}$.

The balance between pro- and anti-inflammatory cytokines is critical to immune regulatory responses. Studying immune system development in ad libitumfed infants, elevated levels of TNF- $\alpha$ were observed in infants fed commercial formula, compared with infants fed breast milk (Kainonen et al., 2013). Commercial infant formulas containing hydrolyzed milk proteins showed immunological activities and inflammatory cytokine induction by both CN and WP (Hochwallner et al., 2017). As relevant to the present study, CN components even in extensively hydrolyzed commercial formulas exhibited an ability to stimulate T-cell proliferation and proinflammatory cytokines IL- 6 and TNF- $\alpha$ secretion (Hochwallner et al., 2017). It may be possible to assume that the higher level of pro-inflammatory cytokines in the piglets fed WP-CN formula was due to peptide release during gastrointestinal digestion of both CN and WP.

The higher feed intake of piglets fed WP-CN formulas than WP formula can also account for the difference in inflammatory responses. A higher concentration of milk proteins in the diet of pigs during the neonatal period was previously shown to modify intestinal immune cell population through antigenic structures, causing a higher colonic permeability and higher secretion of pro-inflammatory cytokines, $\mathrm{TNF}-\alpha$, and IL-1 $\beta$, in re- sponse to induced inflammation in weaned and adult pigs (Boudry et al., 2013). Further investigation of the individual $\mathrm{CN}$ and WP bioactive peptides would provide more exhaustive information about the mechanism of their function in regulating the immune system.

Regardless of composition, all formulas showed a lower induction of IL-6 and TNF- $\alpha$ response compared with the sow-fed piglets. This difference can be attributed to the fact that sow-fed piglets had access to ad libitum feed, and thus, they ingested higher milk protein concentrations. Also, it has been reported that diet-related effects on intestinal immune response are not sex specific until the end of the neonatal period (Boudry et al., 2013).

\section{CONCLUSIONS}

In conclusion, protein compositional differences affected digestive functions and physiological responses. Milk-based formulas containing WP to $\mathrm{CN}$ ratio of 60:40 improved growth performance and feed intake, compared with a WP-based formula. Feed intake was consistent with satiety-related gut hormone, GLP-1, as the formula containing WP promoted higher postprandial plasma GLP-1 concentration, compared with a formula containing WP-CN formula, regardless of the $\beta-\mathrm{CN}$ concentration. Postprandial time positively correlated with plasma GLP-1 concentration. The WP-CN formula promoted a pro-inflammatory milieu by inducing higher secretion of intestinal TNF- $\alpha$, while demonstrating similar influence on IL-6 concentration as WP formula. High and low $\beta-\mathrm{CN}$ at the studied levels similarly influenced inflammatory milieu and postprandial GLP-1 and ghrelin responses. These findings provide a better understanding of the role of protein composition in dairy matrices, and thus can help develop milk protein-based products with improved nutritional and beneficial health properties. The findings also raise an opportunity for research into improving the metabolic and physiological functionality of milk-based products. Further investigations are suggested to be performed on higher levels of $\beta$-CN, and analyzing released peptides sequence and composition in the milk products, to confirm a direct correlation of bioactive peptides functions with metabolism and inflammatory responses in vivo.

\section{ACKNOWLEDGMENTS}

The authors' responsibilities were as follows: MC, MZF, and NRT developed the experimental design; NRT and EA acquired and analyzed the ELISA data; NRT and TA conducted the animal trail; TA conducted the surgical procedure; NRT analyzed the data or per- 
formed statistical analysis; and NRT and MC wrote the manuscript and had primary responsibility for the final content. Conflict of interest and funding disclosure: the authors have no conflict of interest.

\section{REFERENCES}

Barbé, F., S. Le Feunteun, D. Rémond, O. Ménard, J. Jardin, G. Henry, B. Laroche, and D. Dupont. 2014. Tracking the in vivo release of bioactive peptides in the gut during digestion: Mass spectrometry peptidomic characterization of effluents collected in the gut of dairy matrix fed mini-pigs. Food Res. Int. 63:147-156.

Billeaud, C., J. Guillet, and B. Sandler. 1990. Gastric emptying in infants with or without gastro- oesophageal reflux according to the type of milk. Eur. J. Clin. Nutr. 44:577-583.

Boirie, Y., M. Dangin, P. Gachon, M. P. Vasson, J. L. Maubois, and B. Beaufrere. 1997. Slow and fast dietary proteins differently modulate postprandial. Proc. Natl. Acad. Sci. USA 94:14930-14935.

Boudry, C., J. P. Dehoux, J. Wavreille, D. Portetelle, A. Thewis, and A. Buldgen. 2008. Effect of a bovine colostrum whey supplementation on growth performance, faecal Escherichia coli population and systemic immune response of piglets at weaning. Animal $2: 730-737$.

Boudry, G., A. Jamin, L. Chatelais, C. Gras-Le Guen, C. Michel, and I. Le Huërou-Luron. 2013. Dietary protein excess during neonatal life alters colonic microbiota and mucosal response to inflammatory mediators later in life in female pigs. J. Nutr. 143:1225-1232.

Bouzerzour, K., F. Morgan, I. Cuinet, C. Bonhomme, J. Jardin, I. Le Huërou-Luron, and D. Dupont. 2012. In vivo digestion of infant formula in piglets: Protein digestion kinetics and release of bioactive peptides. Br. J. Nutr. 108:2105-2114.

Chatterton, D. E. W., D. N. Nguye, S. B. Bering, and P. T. Sangild. 2013. Anti-inflammatory mechanisms of bioactive milk proteins in the intestine of newborns. Int. J. Biochem. Cell Biol. 45:1730-1747.

Chatterton, D. E. W., J. T. Rasmussen, C. W. Heegaard, E. S. S $\varnothing-$ rensen, and T. E. Petersen. 2004. In vitro digestion of novel milk protein ingredients for use in infant formulas: Research on biological functions. Trends Food Sci. Technol. 15:373-383.

de Lange, C. F. M., J. Pluske, J. Gong, and C. M. Nyachoti. 2010. Strategic use of feed ingredients and feed additives to stimulate gut health and development in young pigs. Livest. Sci. 134:124-134.

de Noni, I. 2008. Release of $\beta$-casomorphins 5 and 7 during simulated gastro-intestinal digestion of bovine $\beta$-casein variants and milkbased infant formulas. Food Chem. 110:897-903.

Fan, M. Z., T. Archbold, D. Lackeyram, Q. Liu, Y. Mine, and G. Paliyath. 2012. Consumption of guar gum and retrograded highamylose corn resistant starch increases IL-10 abundance without affecting pro-inflammatory cytokines in the colon of pigs fed a high-fat diet. J. Anim. Sci. 90:278-280.

Fitzgerald, R. J., and H. Meisel. 2003. Milk protein hydrolysates and bioactive peptides. Pages 675-698 in Advanced Dairy Chemistry. Vol. 1, Proteins. 3rd ed. P. F. Fox and P. L. H. McSweeney, ed. Springer, Boston, MA.

Fleddermann, M., H. Demmelmair, and B. Koletzko. 2014. Energetic efficiency of infant formulae: A review. Ann. Nutr. Metab. 64:276283.

Gibbons, C., P. Caudwell, G. Finlayson, D. L. Webb, P. M. Hellström, E. Näslund, and J. E. Blundell. 2013. Comparison of postprandial profiles of ghrelin, active GLP-1, and total PYY to meals varying in fat and carbohydrate and their association with hunger and the phases of satiety. J. Clin. Endocrinol. Metab. 98:E847-E855.

Gill, H. S., F. Doull, K. J. Rutherfurd, and M. L. Cross. 2000. Immunoregulatory peptides in bovine milk. Br. J. Nutr. 84:S111-S117.

Hall, W. L., D. J. Millward, S. J. Long, and L. M. Morgan. 2003. Casein and whey exert different effects on plasma amino acid profiles, gastrointestinal hormone secretion and appetite. Br. J. Nutr. 89:239-248.

Herfel, T. M., S. K. Jacobi, X. Lin, V. Fellner, D. C. Walker, Z. E. Jouni, and J. Odle. 2011. Polydextrose enrichment of infant for- mula demonstrates prebiotic characteristics by altering intestinal microbiota, organic acid concentrations, and cytokine expression in suckling piglets. J. Nutr. 141:2139-2145.

Hochwallner, H., U. Schulmeister, I. Swoboda, M. Focke-Tejkl, R. Reininger, V. Civaj, R. Campana, J. Thalhamer, S. Scheiblhofer, N. Balic, F. Horak, M. Ollert, N. G. Papadopoulos, S. Quirce, Z Szepfalusi, U. Herz, E. A. F. van Tol, S. Spitzauer, and R. Valenta. 2017. Infant milk formulas differ regarding their allergenic activity and induction of T-cell and cytokine responses. Allergy 72:416-424.

Horner, K., E. Drummond, and L. Brennan. 2016. Bioavailability of milk protein-derived bioactive peptides: A glycaemic management perspective. Nutr. Res. Rev. 29:91-101.

Kainonen, E., S. Rautava, and E. Isolauri. 2013. Immunological programming by breast milk creates an anti-inflammatory cytokine milieu in breast-fed infants compared to formula-fed infants. Br. J. Nutr. 109:1962-1970.

Kim, C. J., J. Kovacs-Nolan, C. Yang, T. Archbold, M. Z. Fan, and Y. Mine. 2009. L-cysteine supplementation attenuates local inflammation and restores gut homeostasis in a porcine model of colitis. Biochim. Biophys. Acta 1790:1161-1169.

Korhonen, H., and A. Pihlanto. 2003. Food-derived bioactive peptides - Opportunities for designing future foods. Curr. Pharm. Des. 9:1297-1308.

Kume, H., K. Okazaki, T. Yamaji, and H. Sasaki. 2012. A newly designed enteral formula containing whey peptides and fermented milk product protects mice against concanavalin A-induced hepatitis by suppressing overproduction of inflammatory cytokines. Clin. Nutr. 31:283-289.

Lackeyram, D., D. Young, C. J. Kim, C. Yang, T. Archbold, Y. Mine, and M. Z. Fan. 2017. Interleukin-10 is differentially expressed in the small intestine and the colon experiencing chronic inflammation and ulcerative colitis induced by dextran sodium sulfate in young pigs. Physiol. Res. 66:147-162.

Lönnerdal, B. 2013. Bioactive proteins in breast milk. J. Paediatr. Child Health 49(Suppl 1):1-7.

Luhovyy, B. L., T. Akhavan, and G. H. Anderson. 2007. Whey proteins in the regulation of food intake and satiety. J. Am. Coll. Nutr. 26:704S-712S.

Meisel, H. 2005. Biochemical properties of peptides encrypted in bovine milk proteins. Curr. Med. Chem. 12:1905-1919.

Miller, E. R., and D. E. Ullrey. 1987. The pig as a model for human nutrition. Annu. Rev. Nutr. 7:361-382.

Moughan, P. J., M. J. Birtles, P. D. Cranwell, W. C. Smith, and M. Pedraza. 1992. The piglet as a model animal for studying aspects of digestion and absorption in milk fed human infants. World Rev. Nutr. Diet. 67:40-113.

Moughan, P. J., P. D. Cranwell, and W. C. Smith. 1991. An evaluation with piglets of bovine milk, hydrolyzed bovine milk, and isolated soybean proteins included in infant milk formulas. II. Stomach emptying rate and the postprandial change in gastric $\mathrm{pH}$ and milk clotting enzyme activity. J. Pediatr. Gastroenterol. Nutr. $12: 253-259$.

NRC. 2012. Nutrient Requirements of Swine. 11th rev. ed. National Academies Press, Washington, DC.

Overduin, J., M. H. C. Schoterman, W. Calame, A. J. Schonewille, and S. J. M. Ten Bruggencate. 2013. Dietary galacto-oligosaccharides and calcium: effects on energy intake, fat-pad weight and satiety-related, gastrointestinal hormones in rats. Br. J. Nutr. 109:1338-1348.

Park, Y. W., and G. F. W. Haenlein. 2006. Human milk. Pages 407420 in Handbook of Milk of Non-Bovine Mammals. Y. W. Park and G. F. W. Haenlein, ed. Blackwell Publ., Ames, IA.

Pezeshki, A., A. Fahim, and P. K. Chelikani. 2015. Dietary whey and casein differentially affect energy balance, gut hormones, glucose metabolism, and taste preference in diet-induced obese rats. J. Nutr. 145:2236-2244.

Pusztai, P., B. Sarman, E. Ruzicska, J. Toke, K. Racz, A. Somogyi, and Z. Tulassay. 2008. Ghrelin: a new peptide regulating the neurohormonal system, energy homeostasis and glucose metabolism. Diabetes Metab. Res. Rev. 24:343-352. 
Rafiee Tari, N., M. Z. Fan, T. Archbold, E. Kristo, A. Guri, E. Arranz, and M. Corredig. 2018. Effect of milk protein composition of a model infant formula on the physicochemical properties of in vivo gastric digestates. J. Dairy Sci. 101:2851-2861.

Räihä, N. C., A. Fazzolari-Nesci, C. Cajozzo, G. Puccio, A. Monestier, G. Moro, I. Minoli, E. Haschke-Becher, C. Bachmann, M. Van't Hof, A.-L. Carrié Fässler, and F. Haschke. 2002. Whey predominant, whey modified infant formula with protein/energy ratio of $1.8 \mathrm{~g} / 100 \mathrm{kcal}$ : Adequate and safe for term infants from birth to four months. J. Pediatr. Gastroenterol. Nutr. 35:275-281.

Ripken, D., N. van der Wielen, J. van der Meulen, T. Schuurman, R. F. Witkamp, H. F. J. Hendriks, and S. J. Koopmans. 2015. Cholecystokinin regulates satiation independently of the abdominal vagal nerve in a pig model of total subdiaphragmatic vagotomy. Physiol. Behav. 139:167-176.
Thompkinson, D. K., and S. Kharb. 2007. Aspects of infant food formulation. Compr. Rev. Food Sci. Food Saf. 6:79-102.

Ul Haq, M. R., R. Kapila, R. Sharma, V. Saliganti, and S. Kapila. 2014. Comparative evaluation of cow $\beta$-casein variants (A1/A2) consumption on $\mathrm{Th}_{2}$-mediated inflammatory response in mouse gut. Eur. J. Nutr. 53:1039-1049.

Veldhorst, M. A. B., A. G. Nieuwenhuizen, A. Hochstenbach-Waelen, A. J. A. H. van Vught, K. R. Westerterp, M. P. K. J. Engelen, R. J. M. Brummer, N. E. P. Deutz, and M. S. Westerterp-Plantenga. 2009. Dose-dependent satiating effect of whey relative to casein or soy. Physiol. Behav. 96:675-682.

Young, D., M. Z. Fan, and Y. Mine. 2010. Egg yolk peptides upregulate glutathione synthesis and antioxidant enzyme activities in a porcine model of intestinal oxidative stress. J. Agric. Food Chem. 58:7624-7633. 